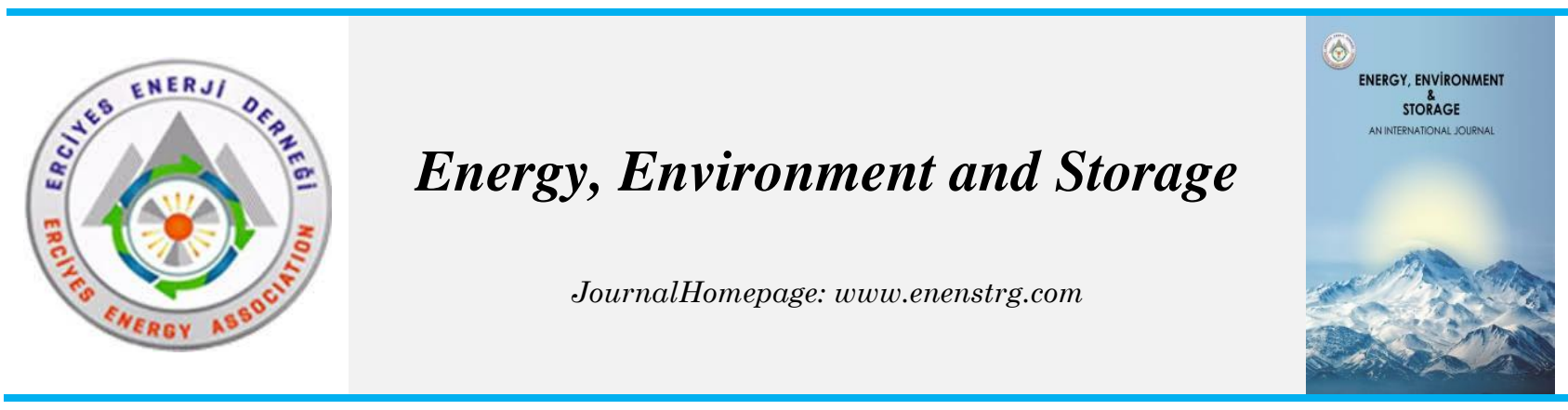

\title{
Application in Virtual System Modelling (VSM) of Sensored Pm BLDC Motor Drive Using Two Technologies of Processors PIC16F877Aand Arduino Uno R3
}

\author{
Ziad Bou Sakr ${ }^{1}$, Claude Ziad El-Bayeh ${ }^{*}$, Mohamed Y. Tarnini ${ }^{1}$ \\ ${ }^{1}$ Faculty of Electrical Engineering, Beirut Arab University, LEBANON; \\ ziad bs@hotmail.com, m.tarnini@bau.edu.lb \\ ${ }^{2 *}$ Canada Excellence Research Chair Team, Concordia University, Canada

\section{c.baveh@hotmail.com; ORCID: 0000-0002-8268-8878}

\begin{abstract}
This paper presents the simulation of a 3-phase Permanent Magnet Brushless DC (PM BLDC) motor drive. For the studied drive system in this paper, pulse width modulation (PWM) control has been implemented for a 60-degree six-step trapezoidal PM BLDC motor drive. The used processor is Arduino and PIC16F877A, which is a common, flashable, and low-cost microcontroller unit (MCU) with functions to perform commutation sequence, rotating direction control, speed control and reading Hall sensor signals, and calculating RPM and duty cycle of the PWM outputs signals depending on variable speed. The controlling technique uses sensored type in order to make this design suitable for low-speed and high-speed applications plus control simplicity. In this paper, The application of Proteus Virtual System Modelling (VSM) software as a real-time simulation tool is introduced to model the performance of a 3-phase Permanent Magnet Brushless DC motor drive before hardware implementation. Expected results can be monitored and analyzed throughout the virtual simulation of all components. The usage of Proteus VSM enables shorter product development time, thus reducing development costs for industrial applications.
\end{abstract}

Keywords:Permanent magnet; BLDC motor; Controller; PWM; Proteus VSM; Arduino.

ArticleHistory: Received:14.08.2021; Revised: 21.08.2021; Accepted:24.08.2021

Doi:https://doi.org/1052924/KKND4173

\section{INTRODUCTION}

In the literature, there are different types of DC motors such as Brushless Direct Current Motor (BLDC) [1], Permanent Magnet Synchronous Motor (PMSM) with a sinusoidal waveform of the Back EMF [2], stepping Motors [3], and Brushed DC motor (BDC) [4]. Stepping Motors are ideally suited for open-loop positioning, also known as BLDC motor sensorless. BLDC machines are the most obvious candidate for high-speed applications, and they are closed-loop positioning by using Hall sensors. BLDC motors are considered one of the best motors that are gaining popularity around the world [5]. BLDC motors are used in industries such as appliances, automotive, aerospace, consumers, medical, industrial automation equipment, and instrumentation [6]. As the name implies, BLDC motors do not use brushes for commutation; instead, they are electronically commutated. BLDC motors have many advantages over brushed DC motors, such as they have (i) better speed versus torque characteristics, (ii) higher dynamic response, (iii) higher efficiency, (iv) longer operating life, (v) noiseless operation, (vi) and higher speed ranges [7]. In addition, the torque ratio is high, and it is delivered to the size of the rotor, which makes it useful in some applications where weight and space are critical factors.

The contribution of the designed circuit is by integrating two different technologies of processor (PIC16F877A) from microchip and Arduino from Atmel. The first processor measures the speed variation of the BLDC motor and displays it on the LCD screen. The result is compared to the second processor that measures speed via VSM (proteus), which provides independence. By using two processors, the performance of the system is improved, and the size of memory is increased. Hence, the system becomes more multitasking.

\section{CONSTRUCTION AND OPERATING PRINCIPLE}

BLDC motor consists of stator, rotor, and position sensor as shown in Figure 1. The rotation of the BLDC motor requires position feedback of relative rotor position. Mostly used BLDC motor uses Hall sensors as the position feedback [8]. In order to produce a rotating field (driving torque), respective phases of the stator have to be turned on and off in sequence through the six switches (usually MOSFET or IGBT) of the three-phase full-bridge 
inverter, depending on the position of the rotor. Position signals from the three Hall sensors are fed back to the controller. Hall signals carry either $0 \mathrm{~V}$ (logic low) or $+5 \mathrm{~V}$ (logic high) depending on the rotor position.
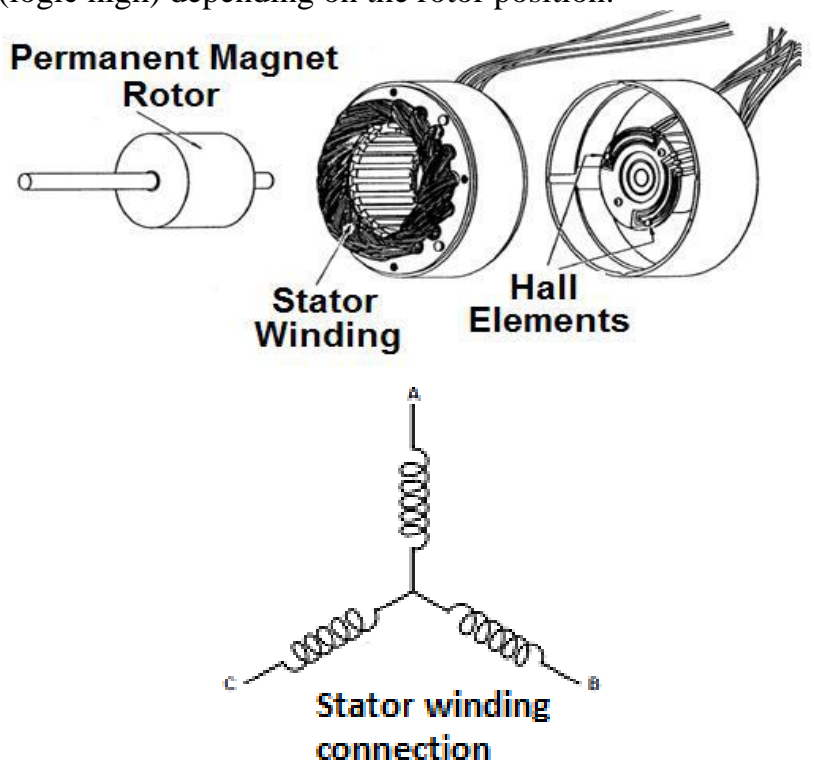

Figure 1. Different parts of sensored BLDC motor [8].

BLDC motors are a type of synchronous motor. It means that the magnetic fields generated by both stators, and rotors, rotate at the same frequency. In addition, they do not experience the "slip" which can be found in induction motors.

\subsection{Stator}

The BLDC motor's stator consists of stacked steel laminations with windings placed in the slots that are axially cut along the inner periphery. Traditionally, the stator resembles the one of an induction motor. However, the windings are distributed in a different manner. Most BLDC motors have three stator windings connected in a star fashion. Each winding has many interconnected coils. At least one coil is placed in the slots, and it is interconnected to other coils to form a winding. Each of these windings is distributed over the stator periphery to form an even number of poles. There are two types of stator windings variants, trapezoidal and sinusoidal machines (also called motors). The difference is made based on the interconnection of coils in the stator windings to give the different types of back Electromotive Force (EMF). The trapezoidal motor provides a back with EMF that forms a trapezoidal waveform, as in Figure 2, while the sinusoidal motor gives a back EMF which forms a sinusoidal waveform, as shown in Figure 3.

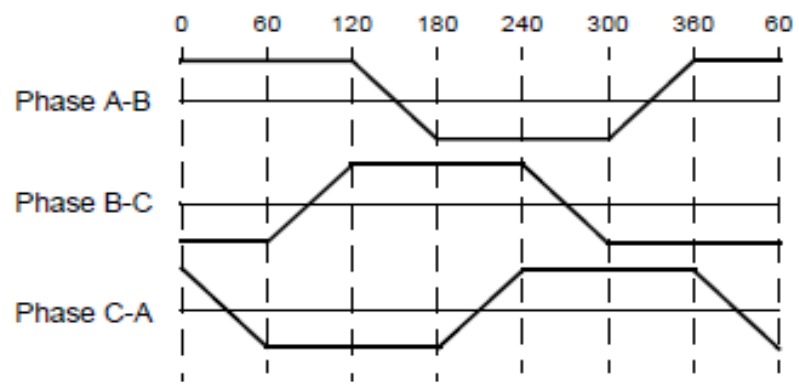

Figure 2: Trapezoidal back EMF [9].

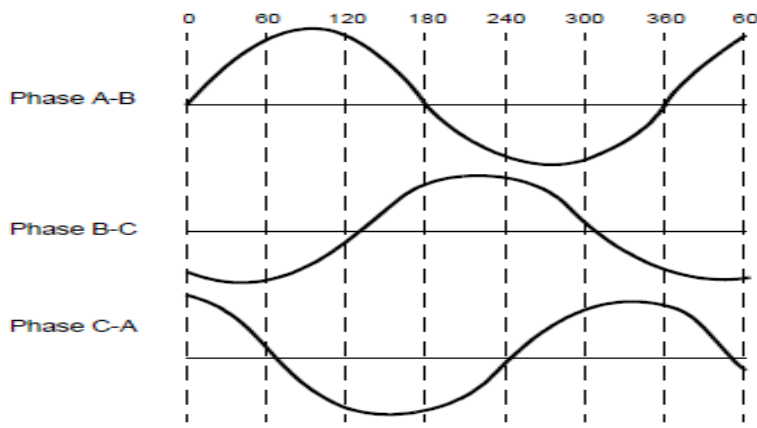

Figure 3: Sinusoidal back EMF [9].

In addition to the back EMF, the phase current also has trapezoidal and sinusoidal variations in the respective types of motors. This makes the output torque by a sinusoidal motor smoother than the one of the trapezoidal motors. However, this comes with an extra cost, as the sinusoidal motors take extra winding interconnections because of the coil's distribution on the stator periphery, thereby increasing the copper intake by the stator windings.

\subsection{Rotor}

The rotor is made of a permanent magnet and can vary from two to eight pole pairs with alternate North $(\mathrm{N})$ and South (S) poles. Based on the required magnetic field density in the rotor, the proper magnetic material is chosen to make the rotor. Permanent magnets are traditionally made of Ferrite magnets. Rare earth alloy magnets are gaining popularity as technology advances. The ferrite magnets are less expensive, but they have the disadvantage of low flux density for a given volume. In contrast, the alloy material has a high magnetic density per volume and enables the rotor to compress further for the same torque. These alloy magnets improve the size-toweight ratio and give higher torque for the same size motor using ferrite magnets. Figure 4 shows cross-sections of different arrangements of magnets in a rotor.
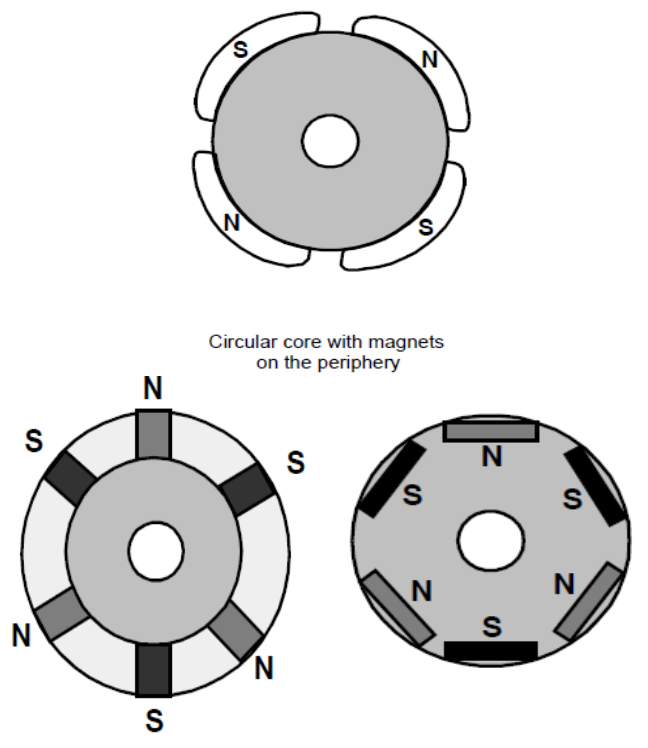

Circular core with rectangular magnets Circular core with rectangular inserted into the rotor core magnets embedded in the ro

Figure 4: Rotor magnet cross-sections [9]. 


\subsection{Hall Sensors}

The Hall Effect theory is described when a currentcarrying conductor or a semiconductor is introduced to a perpendicular magnetic field. A voltage can be measured at the right angle to the current path. This effect of obtaining a measurable voltage is known as the Hall Effect. Unlike a brushed DC motor, the commutation of a BLDC motor is controlled electronically. To rotate the BLDC motor, the stator windings should be energized in a sequence. The rotor position should be determined and known in order to understand which winding will be energized following the energizing sequence. Rotor position is sensed using Hall effect sensors embedded into the stator. Most BLDC motors have three Hall sensors embedded into the stator on the non-driving end of the motor. Whenever the rotor magnetic poles pass near the Hall sensors, they give a high or low signal, indicating the $\mathrm{N}$ or $\mathrm{S}$ pole is passing near the sensors. The exact sequence of commutation can be determined based on the combination of these three Hall sensor signals.

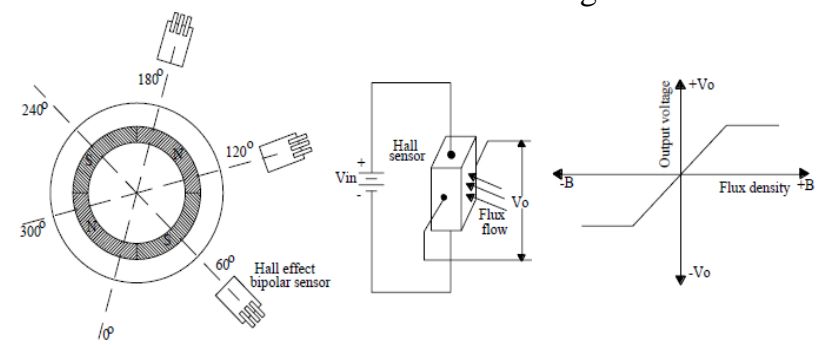

Figure 5: Hall sensor [10].

\section{MATHEMATICAL Modeling OF THE SPEED TORQUE}

After the short introduction of each part of the motor, it is necessary to have a mathematical model of the system which will be described in this section.

Speed torque characteristics of a BLDC motor can be realized from the EMF and voltage equations of the motor. The EMF equation of the BLDC motor is quite simple and resembles the conventional DC motor. Induced EMF in a single coil can be expressed in Equation (1), [10-12].

Where,

$$
e_{p h}=2 B_{g} r l T_{p h} w_{m}
$$

$e_{p h} \quad$ EMF generated per phase in Volt

$B_{g} \quad$ Flux density of air gap in $\mathrm{wb} / \mathrm{m} 2$

$r \quad$ Radius of air gap in $\mathrm{mm}$

$l \quad$ Length of armature in $\mathrm{mm}$

$T_{p h} \quad$ Number of coil turns per phase

$w_{m^{-}} \quad$ Angular velocity in mechanical $\mathrm{rad} / \mathrm{sec}$

Considering another coil connected with slot angle gives equal magnitude. Hence, the resultant induced back EMF per phase is shown in Equation (2), [10-12].

$$
e_{p h}=4 B_{g} r l T_{p h} w_{m}
$$

By considering the back EMF constant $\left(K_{m}=4 B_{g} r l T_{p h}\right)$, the generated back EMF becomes as shown in Equation (3). The voltage equation of BLDC is similar to conventional DC motor and it is presented in Equation (4), [10-12].

$$
\begin{gathered}
e_{p h}=K_{m} w_{m} \\
V=2 e_{p h}+2 I R_{p h}+2 V_{d d}
\end{gathered}
$$

where:

$V \quad$ Supply voltage in Volt

I Armature current in Amp

$R_{p h} \quad$ Armature resistance per phase in Ohm

$V_{d d} \quad$ Voltage drop of the device in Volt

Usually,the voltage drop is neglected, then armature current can be expressed by Equation (5). Equation (6) is obtained by substituting Equation (3) into Equation (5). Equation (6) is obtained by substituting Equation (3) into Equation (5), [10-12]

$$
\begin{aligned}
& I=\left(V-2 e_{p h}\right) / 2 R_{p h} \\
& I=\left(V-K_{m} W_{m}\right) / 2 R_{p h}
\end{aligned}
$$

From Equation (6), the speed of the motor can be expressed as in Equation (7), and the input power of the motor is presented in Equation (8), [10-12].

$$
\begin{gathered}
w_{m}=\left(V-2 I R_{p h}\right) / K_{m} \\
V I=2 I e_{p h}+2 I^{2} R_{p h}+2 V_{d d} I
\end{gathered}
$$

where:

VI Electrical power input in Watts

$2 I e_{p h} \quad$ Power converted as mechanical (Pm) in Watts

$2 I 2 R_{p h} \quad$ Resistive loss of armature winding in Watts

$2 V_{d d} I \quad$ Power loss of device in Watts

Hence the mechanical power developed in the motor is described in Equation (9), and the torque developed in the motor is given by Equation (10), [10-12].

$$
\begin{gathered}
P_{m}=\left(4 B_{g} r l T_{p h}\right) \mathrm{W}_{\mathrm{m}} I \\
T=P_{m} / W_{m}
\end{gathered}
$$

where:

$$
\begin{array}{ll}
T & \text { Torque developed from the motor in Nm } \\
P_{m} & \text { Power developed from the motor in Watts } \\
W_{m} & \text { Speed of motor in } \mathrm{rad} / \mathrm{sec}
\end{array}
$$

By substituting Equation (9) into Equation (10), the final developed torque can be written as in Equation (11), [10$12]$.

$$
T=4 B_{g} r l T_{p h} I
$$

By considering the torque constant $\left(K_{m}=4 B_{g} r l T_{p} I\right)$, the developed torque of the motor becomes equal to Equation (12), [10-12].

$$
T=\mathrm{K}_{\mathrm{m}} I
$$

From this observation, the back EMF constant and the torque constant of the BLDC motor are the same as $K_{m}$. Hence the work of BLDC becomes similar to a conventional DC motor. The speed-torque characteristic of a BLDC is shown in Figure 6. 


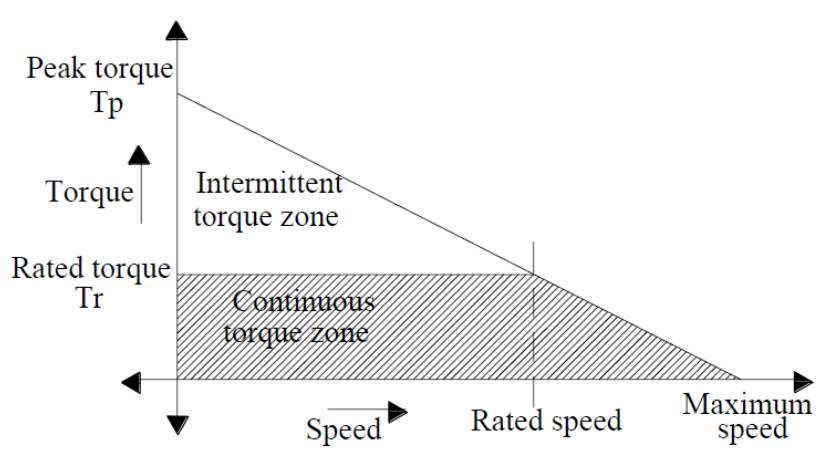

Figure 6: Torque versus speed curve [10].

\section{CIRCUIT DESIGN}

\subsection{Circuit Design and Operation in Proteus (VSM)}

Figure 7 presents the design and operation of a BLDC motor drive circuit using Proteus VSM. The digital pulses from Hall sensors are fed to the microcontroller. The external interrupt is generated on each bit change of any of the three Hall position signal inputs. Special interrupt on bit change is an inherent feature of the Arduino microcontroller, which is useful in designing the motor control algorithm. As soon as any bit change occurs on any one of the three Hall input signals, the program execution sequence skips interrupting address. Six PWM signals are required to drive six MOSFET gates of the three-phase full-bridge inverter. This inverter directly drives the three phases of the BLDC motor. Depending on the rotor position, respective PWM channels are turned on, which in turn drive the respective phases of the BLDC stator through the MOSFETs of the inverter. The proper commutation sequence Clockwise for the respective Hall bit pattern should be stored in a look-up table format in the controller after carrying out proper experiments on the motor. This sequence allows appropriate phase energizing for one-directional rotation continuously performing electronic commutation. For ease of understanding, the developed scheme has been sectionalized into blocks and presented in Figure 8.

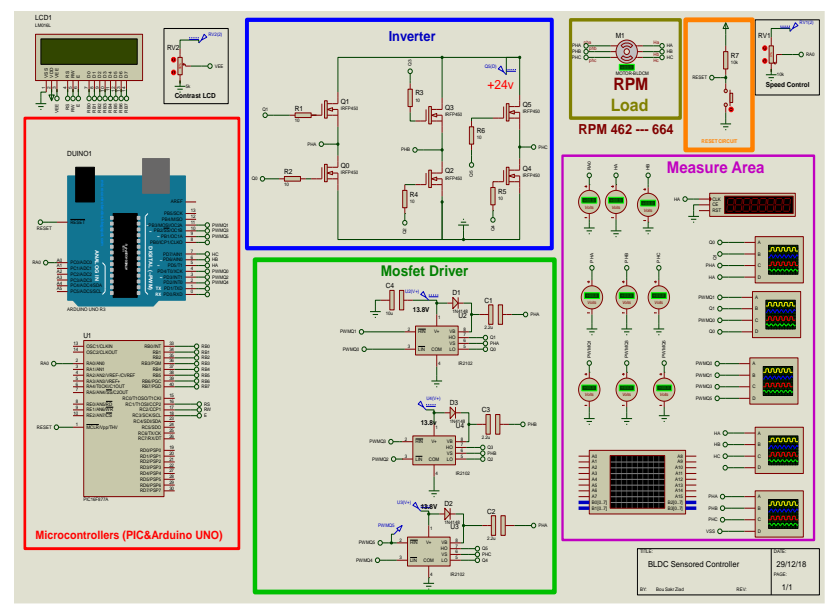

Figure 7: Operation of a BLDC motor drive circuit.

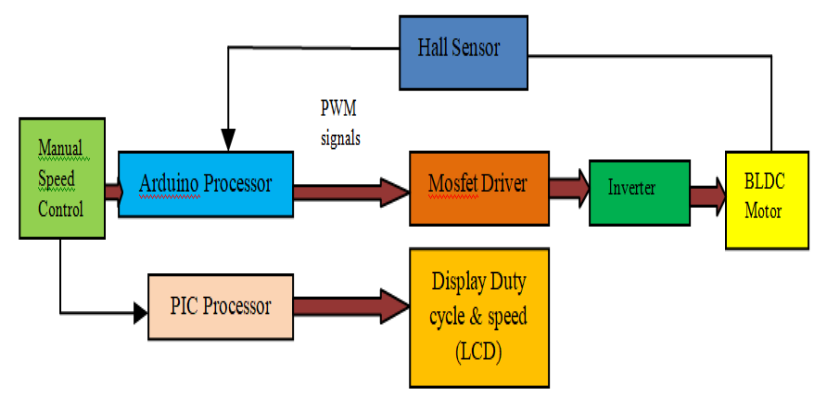

Figure 8: Schematic blocks of the controlled circuit.

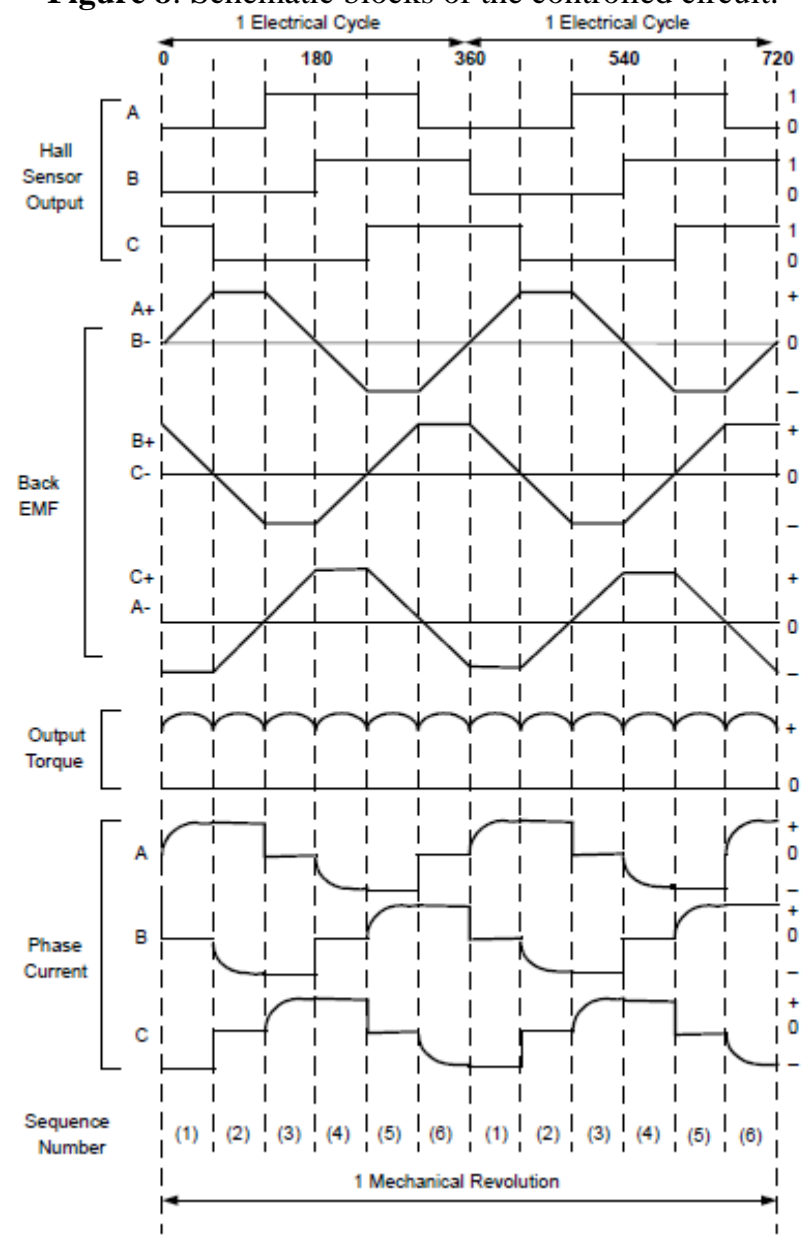

Figure 9: Relationship between the sensors outputs and the required motor drive voltages for phases $\mathrm{A}, \mathrm{B}$, and $\mathrm{C}$ with Back EMF current signals torque [9].

To drive this motor, we need a 3-phase bridge, which has 6 MOSFETs. The general circuit schematic diagram of the 3 -phase bridge is presented in Figure 8. Figure 9 shows the relationship between the sensors' outputs and the required motor drive voltages for phases $\mathrm{A}, \mathrm{B}$, and $\mathrm{C}$ with Back EMF current signals torque.

According to the Hall Effect sensors, the 3-phase bridge is controlled, as shown in Table 1. In the circuit, there are three IR2102 gate driver IC; each one is used to drive one high side MOSFET HIN and one low side MOSFET LIN. The 10k potentiometer is used to control the brushless DC motor speed, and it is controlled using the PWM technique (PWM high sides only). Any time there is one active high side MOSFET and one active low side MOSFET, that means there is always one active PWM pin (Arduino pin 2, 3, and 4). The table below summarizes the active 
Arduino pins according to the hall effect sensors states (pins: 8, 9, and 10).

Table 1. Pins of Arduino processor.

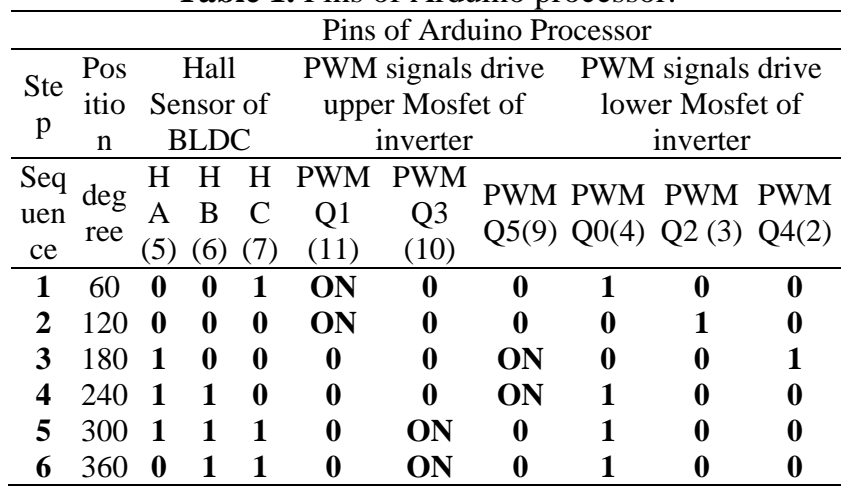

For application purposes, a simple PWM code is written in an Arduino processor because an active PWM signal is needed on pins 9, 10, and 11 (only one is active at a time). Timer2 module is used in this case. The ADC module is configured to read from channel A0 only. The Arduino interrupts on change,and it activates for pins 5, 6, and 7 (hall effect sensors inputs) for better commutation. PORTB are Arduino uno pins: $8 \ldots$ 13. PORTD are Arduino uno pins: 0 .. 7 . Then, the PIC16F877A processor is used to measure the speed of the BLDC motor and the duty cycle of PWM control signals, which depend on variable speed. After that, the speed of the BLDC motor and the duty cycle of the PWM control signals are shown on an LCD display 2lines 32 characters $(2 \times 16)$. Figure 10 presents the flowchart of the code written in the Arduino and PIC16F877A processor.

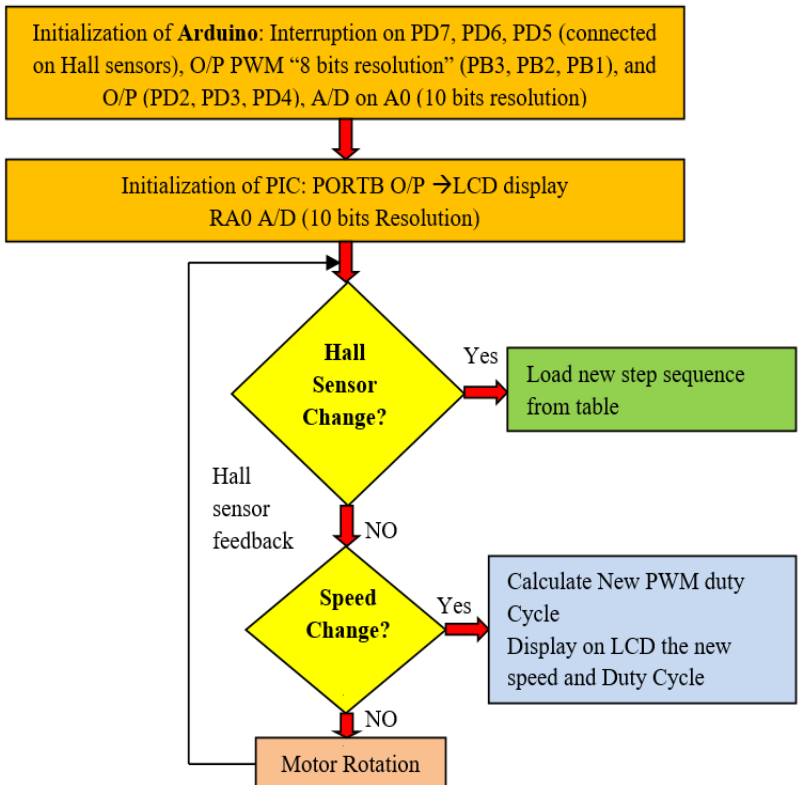

Figure 10: Flowchart of the code written in Arduino and PIC16F877A processor.

\subsection{Different types of control and selected technique}

In the PWM, the voltage supply is chopped at a fixed frequency with a duty cycle depending on the current error. Therefore, both the current and the rate of change of the current can be controlled. The two-phase supply duration is limited by the two-phase commutation angles. The main advantage of the PWM strategy is that the chopping frequency is a fixed parameter. Hence, acoustic and electromagnetic noises are relatively easy to filter.
There are also two ways of handling the drive current switching: hard- and soft-chopping. In the hard-chopping technique, both phase transistors are driven by the same pulse signal: the two transistors are switched on and off at the same time. The soft chopping approach allows not only a control of the current and of the change rate of the current but a minimization of the current ripple as well. In this soft chopping mode, the low side transistor is left ON during the phase supply, and the high side transistor switches according to the pulsed signal. In this case, the power electronics board has to handle six PWM signals. The duty cycle determines the speed of the motor. The desired speed can be obtained by changing the duty cycle. The PWM in the microcontroller is used to control the duty cycle of the BLDC motor. The average voltage in Equation (13), is obtained for various duty cycles. As the duty cycle percentage decreases, the average voltage also decreases from the supply voltage, as shown in Equation (14). In this case, the duty cycle is defined as the percentage of time the motor is ON. Where, Duty Cycle is in (\%), the Pulse Width is equal to the time when the signal is ON or on a higher state. The period is in seconds, and it is equal to the time of one cycle.

$$
\begin{gathered}
\text { Average voltage }=D^{*} V_{\text {in }} \\
\text { Duty Cycle }=100 \% * \text { Pulse Width/Period }
\end{gathered}
$$

\section{RESULTS}

\subsection{Simulation}

By simulating the electronic circuit in figure 7 , we can observe the operation of the BLDC motor. When we change the speed of the motor via a potentiometer, the duty ratio will change also, and we observe the modification on DSO and LCD. The simulation results of BLDC-M using Proteus Design are shown in Figures 11 to 19. The signal outputs of the PWM measured by the DSO are shown in figure 11 . By changing the motor speed, the frequency of the PWM signal should be much higher than the motor's frequency (at least 10 times depending on the change speed. The average voltage applied to the stator reduces; hence, speed control is achieved. To obtain the desired PWM, the program is written for changing the duty cycle ratio. For the unipolar PWM technique, the triggering is applied at either the lower or upper pair of the inverter.

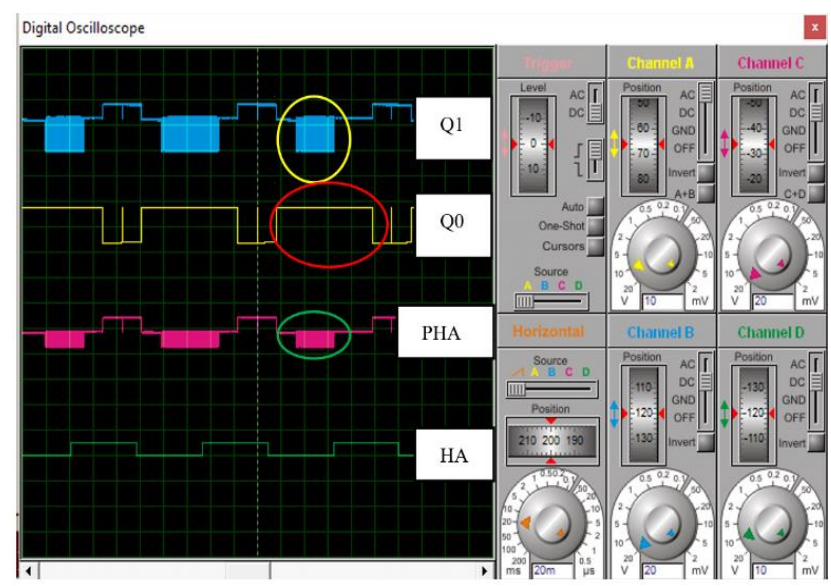

Figure 11: Signal outputs of the PWM measured by the DSO. 
In Figure 11, the yellow (Q0) and red (Q1) circles show the unipolar PWM technique, in which the triggering is applied on the upper MOSFET of the inverter (the amplitude of this signal is $+12 \mathrm{~V}$ ). PHA presents phase A that feeds the coil A of the BLDC motor's stator. The PWM signal can be seen when Q1 output is in the PWM mode (the amplitude signal is +24 Volt). HA is one of the three Hall sensor response signals (the amplitude is $5 \mathrm{~V}$ ). Figure 12 shows a closer look at the PWM in Figure 11, where the PWM period and duty cycle at maximum speed.

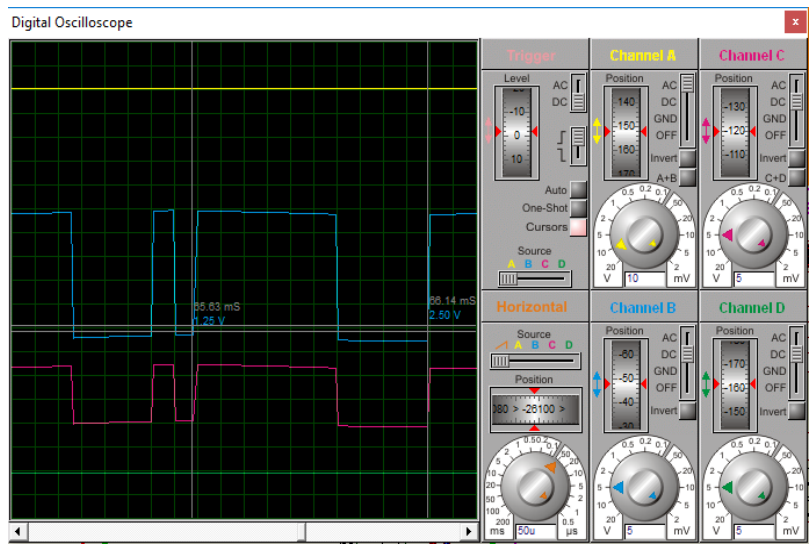

Figure 12:A closer look at the signal outputs of the PWM measured by the DSO.

\subsection{Calculation of the period and duty cycle at} maximum speed

In this case, we assume that the base time of DSO is $50 \mu$ s. The period will be $500 \mu \mathrm{s}(50 \mu \mathrm{s} \times 10)$. The frequency is $F_{\text {measured }}=2 \mathrm{Khz}(1 / 500 \mu \mathrm{s}=2000 \mathrm{~Hz})$. The minimum $\mathrm{f}(\mathrm{PWM})$ signal is $500 \mathrm{~Hz}(10 \times 50 \mathrm{~Hz})$. Therefore, $\mathrm{F}$ (measured) $>\mathrm{f}(\mathrm{PWM})$ and the duty cycle is about $\mathrm{D}=60 \%$ $\left(\mathrm{T}_{\text {on }} / \mathrm{T}=6 / 10\right)$ as presented in Figure 13.

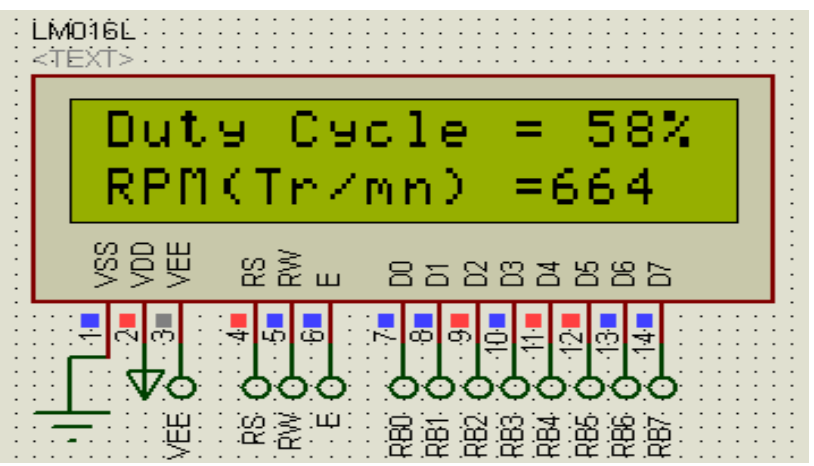

Figure 13: Display of duty cycle and RPM at max speed.

\subsection{Calculation of the period and duty cycle at medium speed}

In Figure 14, by reading between cursors, the period becomes $T_{\text {total }}=510 \mu \mathrm{s},(273.66 \mathrm{~ms}-273.16 \mathrm{~ms}=0.51 \mathrm{~ms})$. It is important to note that the PWM frequency is stable, but the duty cycle changes, and it becomes equal to $\mathrm{D}^{\prime}=28 \%$ $(0.14 \mathrm{~ms} / 0.5 \mathrm{~ms})$ as in Figure $15 . T_{o n}=0.13 \mathrm{~ms}(273.16 \mathrm{~ms}-$ $273.03 \mathrm{~ms})$. The signal on pin PWMQ1 is depicted in Figure 16.

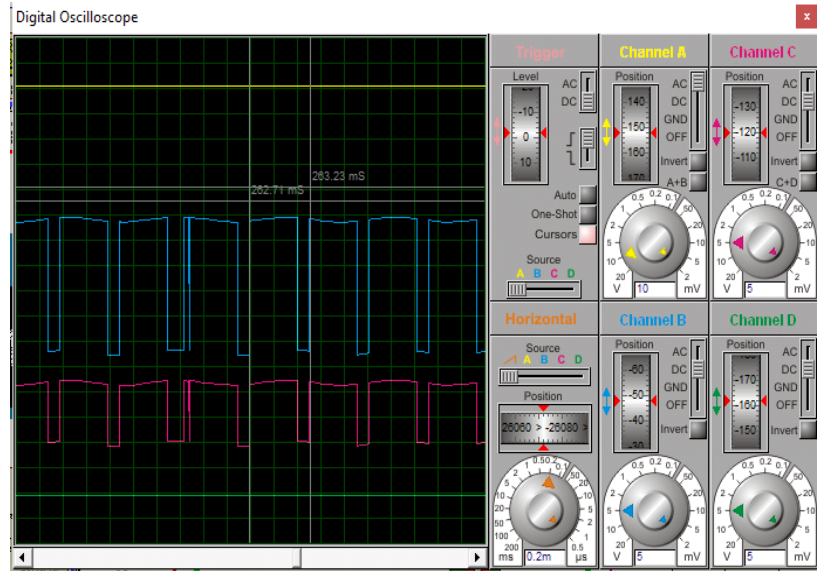

Figure 14: Signal outputs of the PWM at medium speed.

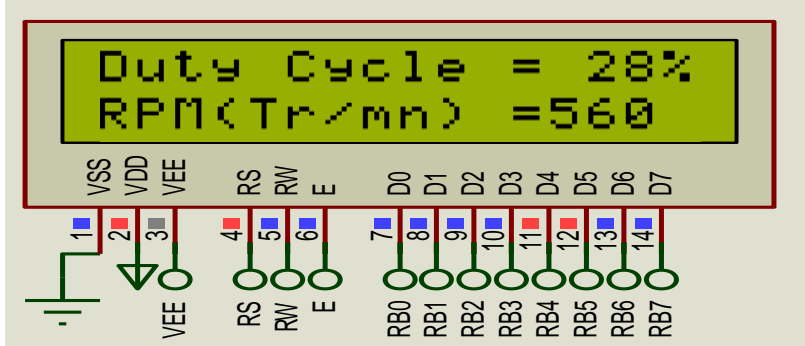

Figure 15: Duty cycle and RPM calculated by the software.

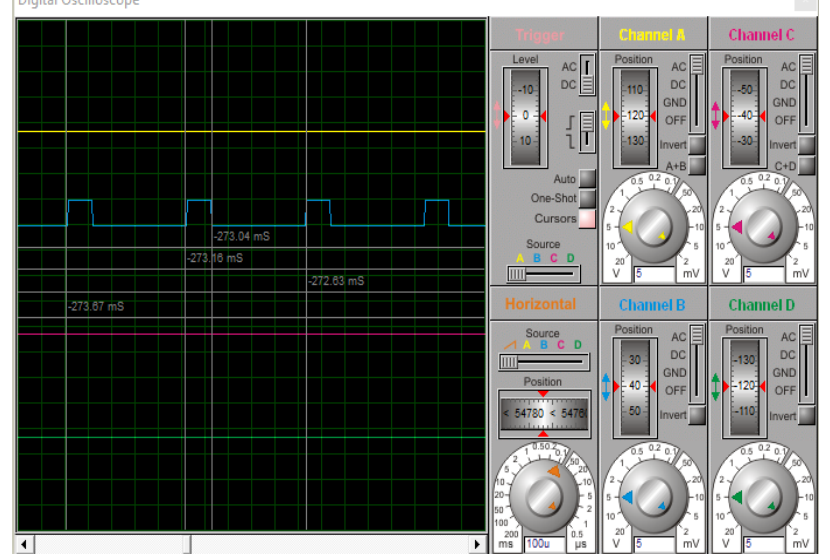

Figure 16: Signal on pin PWMQ1.

\subsection{Calculation of the period and duty cycle at minimum speed}

In figure 17, the LCD display shows the speed and the duty cycle when the $\mathrm{RA}_{0}=0 \mathrm{~V}$. Figure 18 shows the three phases PHA, PHB, and PHC, when these signals have a shape of trapezoidal Back EMF.

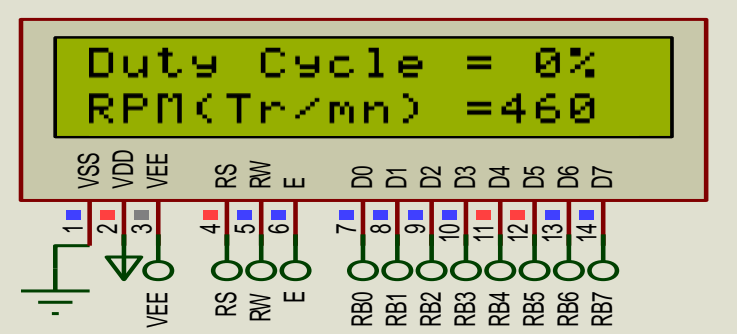

Figure 17: Duty cycle at minimum speed. 


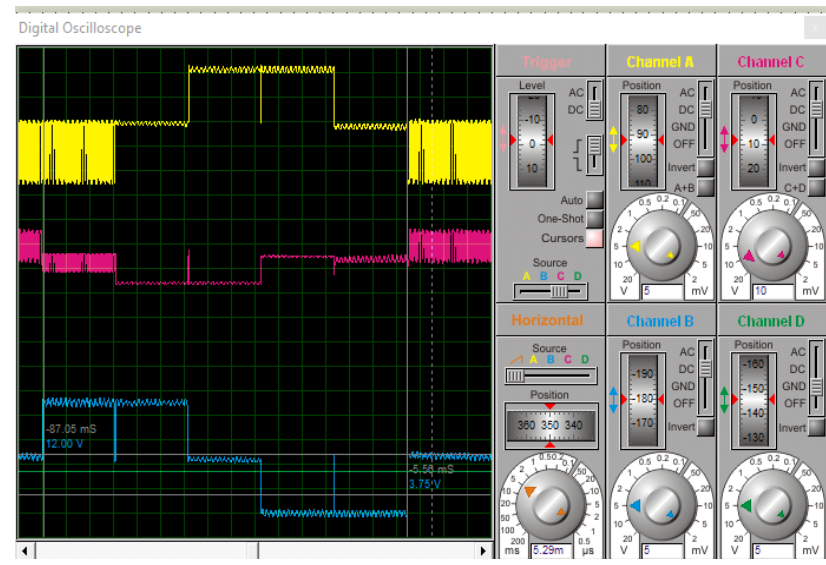

Figure 18: Phase A, B, C signals of BLDC motor.

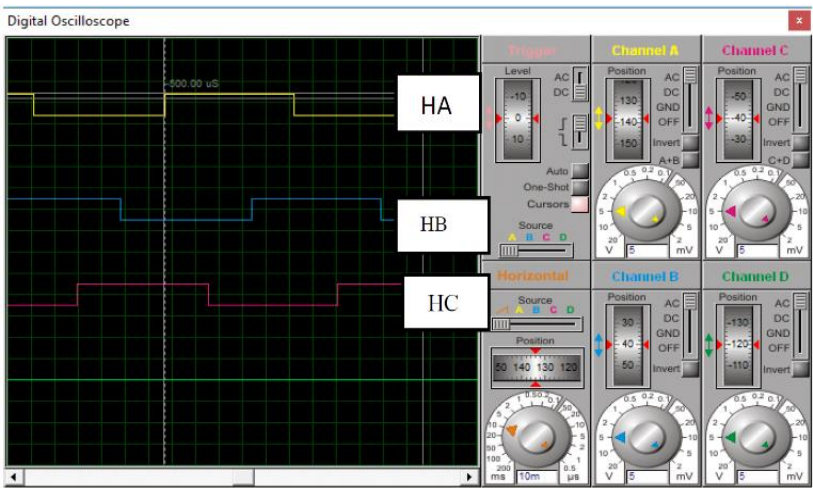

Figure 19: Response of Hall sensors depending on BLDC motor position.

\subsection{Reverse rotation direction of BLDC motor}

To reverse the rotation of the BLDC motor, we swap two Hall sensor wires (HB \& HC) and two-phase wires (PHB $\&$ PHC) by using two relays controlled via Arduino (PB4 \& PB5), which is considered as a hardware solution. The software solution that is used in our circuit can work by swapping the signals generated on (PWMQ5 \& PWMQ3) and (PWMQ2 \& PWMQ4). At the same time, detecting signals received by $\mathrm{HB}$ instead of $\mathrm{HC}$ and vice versa without changing wire connections of the circuit but by swapping a loop function in Arduino program when activating reverse direction by the user.

\section{CONCLUSION}

In this paper, two different technologies of processors are used, PIC and Arduino, in the same simulator (Proteus). Results show that it is beneficial to combine the two processors to enhance the control system of the BLDC motor with Hall effect sensor and BLDC-motor sensorless (Stepper Motor). The proposed combination enlarges the size of the memory program. Hence, it is possible to apply this method in order to reduce ripple torque by using Matlab/Simulink, and convert the solution of the Simulink to Arduino and PIC processors. This can be done by making segmentation of program and each processor execute a part of the task. The communication between multiple processors enhances the efficiency of analysis by executing complex mathematical equations like integral and differential (PID) and enriches the interface communication with different terminals. The disadvantages of the combination of Arduino and PIC in the same circuit is presented as follows, (i) each microcontroller has a specific current limit and input voltage (e.g., PIC's current limit has an average of $25 \mathrm{~mA}$, while Arduino's current limit has an average of $40 \mathrm{~mA}$ ); (ii) the input voltage in Arduino should be between 7-12V, while it should not exceed $5 \mathrm{~V}$ for the case of a PIC. Therefore, we should take into account these differences in wiring connections. This paper presents a prototype work that realizes a solution to the control system. Finally, double verification is made by reading the results from DSO (oscilloscope) and confirming them using the proposed algorithm through a second processor (PIC) with a numerical solution. Therefore, the proposed method becomes easier for the user and more efficient.

\section{REFERENCES}

[1] Sutar, G. A. (2016). Implementation and study of BLDC motor drive system. International Journal of Engineering Sciences and Research Technology, 5, 57-64. [2] Li, Y., Xing, J., Wang, T., \& Lu, Y. (2008). Programmable design of magnet shape for permanentmagnet synchronous motors with sinusoidal back EMF waveforms. IEEE transactions on magnetics, 44(9), 21632167.

[3]Acarnley, P. P. (2002). Stepping motors: a guide to theory and practice (No. 63). IET.

[4]Derammelaere, Stijn, MichielHaemers, Jasper De Viaene, Florian Verbelen, and Kurt Stockman. "A quantitative comparison between BLDC, PMSM, brushed DC and stepping motor technologies." In 2016 19th International Conference on Electrical Machines and Systems (ICEMS), pp. 1-5. Ieee, 2016.

[5]Baldursson, S. (2005). Bldc motor modelling and control-a matlab/simulink implementation (Master's thesis).

[6]Nadolski, R., Ludwinek, K., Staszak, J., \&Jaśkiewicz, M. (2012). Utilization of BLDC motor in electrical vehicles. PrzegladElektrotechniczny, 88(4), 180-186.

[7] Kumar, P., \& Bauer, P. (2008). Improved analytical model of a permanent-magnet brushless DC motor. IEEE Transactions on Magnetics, 44(10), 2299-2309.

[8] Mukherjee, A., Ray, S., \& Das, A. (2014). Development of microcontroller based speed control scheme of BLDC motor using proteus VSM software. International Journal of Electronics and Electrical Engineering, 2(1), 1-7.

[9]Yedamale, P. (2003). Brushless DC (BLDC) motor fundamentals. Microchip Technology Inc, 20, 3-15.

[10] Manikandan, R. An intelligent position controller for vertical rotating single arm robot using BLDC servo drive. Master Thesis, Anna University, 2017.

[11] Ramesh, M. V., Rao, G. S., Amarnath, J., Kamakshaiah, S., \& Jawaharlal, B. (2011, December). Speed torque characteristics of brushless DC motor in either direction on load using ARM controller. In ISGT2011-India (pp. 217-222). IEEE.

[12] Bektas, Y., \&Serteller, N. F. O. (2011). Brushless direct current (BLDC) motor driving experimental set. Energy Education Science and Technology Part A-Energy Science and Research, 27(2), 455-466. 